\title{
CONQUISTAS E DESAFIOS DAS POLITICAS PÚBLICAS PARA A MATERNIDADE: REFLEXÕES SOBRE A LICENÇA PARENTAL COMO INSTRUMENTO DE EQUIDADE DE GÊNERO
}

ACHIEVEMENTS AND CHALLENGES OF MATERNITY PUBLIC POLICIES: REFLECTIONS ABOUT PARENTAL LEAVE AS GENDER EQUITY TOOLS

\section{Fernanda Sena Fernandes ${ }^{1}$, Janaína Xavier Nascimento ${ }^{2}$}

RECEBIDO EM: 15/10/2019 | ACEITO EM: 23/07/2020

DOI: $10.5902 / 2317175840576$

\section{RESUMO}

Este artigo se propõe a analisar, através de pesquisa bibliográfica e pesquisa documental, as conquistas e os desafios das políticas públicas para a maternidade no Brasil, com enfoque na discussão sobre a licença parental e seus possíveis impactos nas políticas de equidade de gênero. Para tanto, após uma discussão inicial do conceito de políticas públicas, analisaremos as políticas públicas para a maternidade implementadas no país ao longo dos séculos XX e XXI. Em seguida, será examinado como tais políticas estiveram permeadas por visões tradicionais de papéis de gênero, segundo as quais caberia prioritariamente às mulheres o cuidado dos filhos e filhas e, aos homens, o provimento dos recursos materiais necessários à manutenção da família. Por fim, discutem-se os efeitos da licença maternidade sobre a reprodução da divisão sexual do trabalho, bem como a licença parental como instrumento da equidade de gênero a partir de um comparativo com o modelo sueco e com modelos latino-americanos, refletindo sobre as potenciais mudanças culturais que poderiam advir dessa alteração.

Palavras-chave: Políticas Públicas; Gênero; Maternidade; Parentalidade.

\footnotetext{
1 Estudante de Graduação em Licenciatura em Ciências Sociais pela Universidade Federal de Santa Maria Lattes: http://lattes.cnpq.br/6682898987113208. Universidade Federal de Santa Maria. Brasil

2 Professora Adjunta no Departamento de Ciências Sociais da Universidade Federal de Santa Maria; Dra. em Sociologia Política pela UFSC/Freie Universität Berlin.

Lattes: http://lattes.cnpq.br/0500517652436194. Universidade Federal de Santa Maria. Brasil
} 
CONQUISTAS E DESAFIOS DAS POLÍTICAS PÚBLICAS PARA A MATERNIDADE:

REFLEXÕES SOBRE A LICENÇA PARENTAL COMO INSTRUMENTO DE EQUIDADE DE GÊNERO

\begin{abstract}
This article intends to analyze, through bibliographical and documental research, the achievements and challenges of maternity public policies in Brazil, focusing on the discussion about parental leave and its possible impacts on gender equity policies. For this purpose, after an initial discussion about the concept of public policies we analyze the maternity policies implemented in the country through the $X X$ and $X X I$ centuries. Then, we examine how these policies were permeated by traditional views of gender roles, according to which childcare is mainly up to women, while the provision of material resources needed for the family's maintenance is mostly up to men. Lastly, the effects of maternity leave over the reproduction of the sexual division of labor are discussed, just as the parental leave as a gender equity tool is discussed from a comparison with the Swedish model, and with Latin American models, with reflections about the potential cultural changes that could come from this modification.

Keywords: Public Policies; Gender; Maternity; Parenting.
\end{abstract}

\title{
1 Introdução
}

As políticas públicas e, mais especificamente, as sociais impactam fortemente sobre o bem-estar dos indivíduos. Nessa perspectiva, utilizar-se de gênero como categoria de análise para estudar as políticas públicas e sociais consiste em entender que, ao analisar as opressões que as mulheres sofrem, tentamos compreender a relação entre os gêneros e seu reflexo nas estruturas sociais e de poder existentes. Debater possibilidades de mudanças a partir dessas estruturas consiste em uma estratégia fundamental, tendo potenciais desdobramentos teóricos e políticos. A divisão sexual do trabalho "tem por características a destinação prioritária dos homens à esfera produtiva e das mulheres à esfera reprodutiva" (KERGOAT, 2003, p. 55). Esse pensamento constitui um dos pilares que sustentam a desigualdade entre homens e mulheres, mesmo que, hoje, as mulheres estejam massivamente inseridas no mercado de trabalho, de maneira formal ou informal. Segundo dados do Instituto Brasileiro de Geografia e Estatística (IBGE) de 2018, o trabalho no âmbito doméstico permanece fazendo com que as mulheres empreguem até $73 \%$ mais horas em trabalhos domésticos que os homens, sendo que os cuidados com os filhos somam boa parte desse percentual. Poderia, nesse contexto, a licença parental surgir como alternativa para a diminuição dos impactos da divisão sexual do trabalho?

Essa assimetria entre os papéis parentais se origina de construções sociais em torno da representação da dicotomia masculino/feminino, em que, historicamente, as mulheres foram confinadas ao espaço privado e os homens colocados no espaço público. Assim, apesar das mudanças nas relações de gênero que vêm ocorrendo nas últimas décadas - com mulheres adquirindo maior espaço na esfera pública e, aos poucos, os homens assumindo sua paternagem -, as políticas públicas brasileiras dirigidas à maternidade não as têm acompanhado, adotando como norte um modelo de família tradicional, cujas contribuições efetivas à emancipação das mulheres e à equidade de gênero ainda são 
incertas. Prova disso é que se por um lado nossas leis trabalhistas representam um progresso significativo em relação à garantia de direitos das mães trabaIhadoras, por outro mostram-se anacrônicas, com poucas mudanças ocorridas em relação à licença-paternidade. Ou seja: subjetivamente, o homem ainda se mantém no papel de provedor, sendo dado pouco estímulo em direção a uma mudança cultural em relação à divisão dos cuidados com os filhos.

Assim, refletindo acerca da licença parental, buscamos compreender os possíveis impactos de sua adoção na sociedade brasileira no que tange à equidade de gênero. Para isso, serão considerados casos de outros países, nos quais a implementação dessa política já é uma realidade, como a Suécia, que nos fornece dados empíricos devido às mais de quatro décadas da implementação, assim como Chile e Uruguai, países latinos que adotaram recentemente essas políticas e com realidades mais semelhantes às especificidades do contexto sociocultural brasileiro.

\section{Políticas públicas e gênero: algumas discussões conceituais}

Por políticas públicas podemos entender o conjunto de medidas adotadas pelo Estado com a finalidade de garantir serviços que proporcionem o bem-estar da população, tais como saúde, educação, redistribuição de renda, seguridade social etc. Assim, estudos referentes à vida dos trabalhadores ingleses, abordando suas dificuldades, misérias e demandas diante de jornadas de trabalho exaustivas, assim como as precárias condições de trabalho e os salários baixos, foram feitos a partir da década de 1830 por instituições filantrópicas e pela Igreja. Esses estudos tinham como principal foco os filhos da classe trabalhadora, em um contexto em que a figura da criança começava a adquirir centralidade tanto nos lares quanto na discussão pública, moldando a noção moderna de infância que nos é dada nos dias de hoje. Além disso, na conjuntura do século XIX, num período de ebulições revolucionárias, iniciava-se a construção de um discurso nacionalista como resposta às agitações que ocorriam por toda a Europa. Esses eventos perpassavam a concepção de filhos da nação, crianças que seriam o pilar dessas identidades nacionais.

Mesmo com a resistência dos movimentos liberais, que viam a possível intervenção do Estado como grave quebra dos princípios de liberdade individual, a necessidade de políticas assistencialistas se sobrepôs, em virtude, por exemplo, das altas taxas de mortalidade infantil e materna. Assim, políticas públicas para a maternidade começaram a ser implementadas a partir da ideia da família como o primeiro núcleo estruturante da sociedade, dentro dessa mesma visão nacionalista (MARTINS, 2010, p.101), visto que as mães eram a fonte de acesso ao bem-estar das crianças. Essas políticas adquiriram força após a Segunda Guerra Mundial, o que Marshall (1967, p. 59) concebeu como a intervenção do Estado, não no sentido de diminuir ou mesmo abolir as estratificações de classe, mas de garantir uma igualdade de exercício de cidadania. 
CONQUISTAS E DESAFIOS DAS POLITICAS PÚBLICAS PARA A MATERNIDADE:

REFLEXÕES SOBRE A LICENÇA PARENTAL COMO INSTRUMENTO DE EQUIDADE DE GÊNERO

Porém, como relata Walby (2004, p. 170), há, na teoria política de Marshall e na sua concepção de cidadania, uma omissão em relação às mulheres, sendo o próprio conceito de participação política restrito ao universalismo masculino. Nesse sentido, o conceito de gênero como categoria de análise não é concebido como o estudo exclusivo da história das mulheres, mas da relação entre os gêneros, útil para compreender os desdobramentos políticos e sociais, assim como as estruturas de opressão geradas por essa relação (SCOTT, 1986, p. 5).

Importante lembrar que, quando nos referimos a gênero, não estamos nos referindo ao sexo biológico, mas às construções socioculturais que representam o que é ser homem e o que é ser mulher, as quais vêm sendo investigadas em diversas áreas do conhecimento. Em seu estudo pioneiro de 1935, Margareth Mead (2009) traçou, em três sociedades polinésias, representações distintas dos papéis de gênero, as quais se diferenciavam da nossa representação ocidental. Na filosofia, Simone de Beauvoir afirma que a biologia não é o suficiente para explicar a condição feminina (2016, p. 65). Em sua pesquisa historiográfica sobre a visão do gênero biológico ao longo da história da anatomia, Thomas Laqueur afirma: "quanto mais examino os registros históricos, menos clara se torna a divisão sexual; quanto mais o corpo existia como o fundamento do sexo, menos sólidas se tornavam as fronteiras" (2001, p. 8). Estamos, portanto, tratando de signos sociais que acabam tendo impacto social nas relações entre os gêneros, inclusive nas políticas públicas.

Ao investigarmos a implementação dessas políticas voltadas à maternidade, especialmente no contexto brasileiro, e suas consequentes repercussões, percebemos que, ao longo do tempo, elas foram aprimoradas, especialmente no período democrático, de forma a abarcar as demandas dos movimentos de mulheres e do movimento feminista, oferecendo uma nova gama de direitos. No entanto, em alguns aspectos, essas políticas precisam de atualizações a fim de acompanharem novas reivindicações em prol de um caminho de erradicação da desigualdade de gênero.

\section{As políticas públicas para maternidade no Brasil}

Historicamente, a questão da cidadania no Brasil é pauta complexa, sendo permeada por rupturas, exclusões de grupos minoritários e falta de políticas que garantam seu exercício a todos. Em um país com fortes raízes oligárquicas, um profundo conflito de classes e uma democracia instável - que sofreu diversas interrupções e foi exercida, por muito tempo, por grupos de elite -, é louvável os avanços que temos em termos de políticas públicas. Esses avanços se devem a vários fatores, como a luta dos movimentos sociais organizados desde o início do século XX, as políticas populistas de Getúlio Vargas nos anos 1930 e a pressão de órgãos internacionais, como a Organização Internacional do Trabalho (OIT). 
As políticas públicas para a maternidade, especificamente, originaram-se na virada do século XIX para o século XX, com a chegada dos ideais higienistas e eugenistas ao Brasil, juntamente com a medicalização de práticas de cura antes pautadas na tradição, como o parto e aos cuidados no período de puerpério, exercidos, até então, de maneira quase que exclusiva por mulheres parteiras e/ou benzedeiras. Esse projeto higienista, voltado a uma perspectiva cientificista, buscava, por um lado, a erradicação das práticas dos saberes populares em nome da ciência e do tecnicismo (WITTER, 2001, p. 11); por outro, regulamentava os corpos femininos, valendo-se, para tanto, do discurso científico. (BESSE, 1999, p. 7). Com grupos de médicos cada vez mais organizados, o debate em torno da medicalização do parto e, consequentemente, da assistência às mães de camadas mais baixas ganhou força e o movimento higienista passou a pressionar de maneira mais efetiva o Estado. No entanto, claramente, o objeto dessas acaloradas discussões não era, de fato, o bem-estar das mães. Prova disso é o artigo publicado, em 1947, pelo Dr. Eurico Carneiro, médico da Legião Brasileira de Assistência. Nesse texto, o médico afirmava que as mães deveriam "oferecer à nacionalidade mais um par de braços robustos e mais uma inteligência". Em outro trecho, ele é ainda mais categórico: "Mas preste atenção: é necessário que também você concorra com sua parte ao entregar à Pátria uma criança de que a Pátria se ufane, jamais um monstrozinho raquítico, macilento ou tarado" (CARNEIRO, 1947 apud MARTINS, 2010).

Com esse apelo nacionalista e, até mesmo, integralista, mesmo os mais ferrenhos liberais, que viam na intervenção da vida familiar grave delito aos princípios de liberdade e individualidade, acabaram por ceder. Assim, diversas convenções foram realizadas com a pauta da regulamentação de políticas que combateriam as altas taxas de mortalidade infantil e materna, resultando, em 1922, na primeira lei voltada a este fim. A implementação dessa lei ocorreu durante o governo Arthur Bernardes, que instituiu o Departamento Nacional de Saúde Pública, o qual tinha como um de seus objetivos tratar das questões da saúde materna e infantil.

Ainda que determinadas medidas fossem tomadas nesse sentido, uma legislação de fato concreta a respeito do tema só foi possível com a promulgação da Constituição de 1934, durante a Era Vargas. Nessa constituição, Getúlio acatou as recomendações da Organização Internacional do Trabalho, através da implementação das Leis Trabalhistas ${ }^{3}$, em 1943. Fundada em 1919, após o Tratado de Versalhes, a OIT realizou, no mesmo ano, a Convenção $n^{\circ} 3$, que tratava da regulamentação do trabalho feminino. Dentre as resoluções, estavam a licença-maternidade de seis semanas antes e seis semanas após o parto, o pagamento de um abono durante o período de afastamento das mães e a proibição da demissão em razão da maternidade. Essas resoluções foram conquistadas e postas como metas a serem cumpridas pelos países signatários dentre eles, o Brasil. Essas medidas foram parcialmente adotadas no contexto brasileiro anterior a Vargas, mas nunca de maneira efetiva (RÉA, 2002, p. 393).

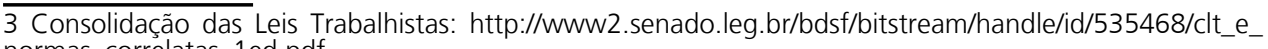
normas_correlatas_1ed.pdf 
CONQUISTAS E DESAFIOS DAS POLITICAS PÚBLICAS PARA A MATERNIDADE:

REFLEXÕES SOBRE A LICENÇA PARENTAL COMO INSTRUMENTO DE EQUIDADE DE GÊNERO

Porém, ainda que dentro de um contexto histórico em que as mulheres começavam a dar passos em relação à conquista da cidadania, a adoção de leis trabalhistas que garantissem a permanência das mulheres no mercado de trabalho e assegurassem direitos às mães trabalhadoras ainda era permeada de um forte caráter regulador e patriarcal. Prova disso eram os artigos sancionados na CLT que restringiam as mulheres ao exercício de determinadas funções, geralmente transposições dos trabalhos domésticos para o âmbito público, como secretárias, professoras e enfermeiras (BESSE, 1999, p. 153). Ademais, tais artigos instituíam o poder de o marido solicitar a demissão da esposa caso não concordasse com a função desempenhada por ela, bem como proibi-la de exercer trabalhos noturnos. Esse viés das leis trabalhistas seguiu sem grandes mudanças mesmo com o período democrático subsequente à Era Vargas e, especialmente, durante a Ditadura Civil-Militar.

Num sentido mais voltado para um caráter emancipatório, as políticas públicas só seriam reformuladas durante a abertura democrática, especialmente através da Constituinte que debateu e redigiu o que mais tarde veio a se tornar a "Constituição Cidadã" de $1988^{4}$. Os direitos ali conquistados foram fruto de intensa militância e articulação do movimento feminista e do movimento de mulheres, especialmente através do Conselho Nacional dos Direitos das Mulheres, criado pela ala feminina do PMDB, que se articulou com coletivos feministas e movimentos de mulheres. A partir dessa mobilização, criou-se a "Carta das Mulheres", que pode ser considerado o documento mais importante do feminismo brasileiro contemporâneo. Dividido em duas partes, o documento trazia reivindicações sobre diversos âmbitos, como vida familiar, trabalho e saúde das mulheres (PINTO, 2003, p. 75).

No fim, a Constituição foi aprovada com a adoção de boa parte da Carta encaminhada pelo movimento feminista e de mulheres acatando, no caso das mães trabalhadoras, reformas importantes na CLT, como a ampliação da licença-maternidade para 120 dias e a proteção do vínculo empregatício desde a confirmação da gravidez até 5 meses após o parto. Ainda, foram asseguradas a licença-maternidade para mães adotantes, com a garantia de abono salarial igual ao da mãe biológica, e a proibição de práticas discriminatórias quanto à maternidade em entrevistas de emprego. Além disso, modificações na Lei de Diretrizes e Bases $^{5}$, de 1996, também trouxeram importantes conquistas para a emancipação feminina ao ser determinado o acolhimento obrigatório, de crianças a partir dos 3 anos de idade, em creches e escolas públicas, além da disponibilidade de vagas, pelos municípios, para crianças de 0 a 3 anos $^{6}$.

No entanto, é necessário assinalar que, embora a Constituição de 1988 ter consolidado diversas demandas das mulheres, ainda há aspectos impor-

\footnotetext{
4 Constituição Federal: https://www2.senado.leg.br/bdsf/bitstream/handle/id/518231/CF88_Livro_ EC91 2016.pdf

5 Lei de Diretrizes e Bases da Educação: https:/www2 senado.leg.br/bdsf/bitstream/handle/id/70320/65.pdf

6 É importante destacar que, apesar de configurar um importante avanço em relação ao direito das crianças de acesso à educação e de assistência às mães, essa disponibilidade de vagas, apesar de obrigatória, não tem regulamentação do número de vagas sobre o número de habitantes, sendo, algumas vezes, insuficiente frente à demanda.
} 
tantes a serem conquistados, tais como: a ampliação dos direitos reprodutivos, especialmente em relação à questão da descriminalização do aborto; a luta por igualdade salarial, que, mesmo garantida pelo texto da Constituição, ainda está longe de ser material; a ampliação das redes de apoio às mulheres vítimas de violência doméstica, o que se atrela à necessidade de treinamento de órgãos como polícia e judiciário para tratar do tema; e a obrigatoriedade de um número mínimo de vagas para crianças de 0 a 3 anos e a necessidade do atendimento integral nas escolas, não apenas por uma questão de facilitar o acesso das mulheres ao mercado de trabalho, mas de promoção do desenvolvimento infantil. Ademais, também é necessário um debate mais incisivo sobre as políticas de equidade de gênero, a exemplo da licença parental, que incidiria diretamente na divisão sexual do trabalho e, consequentemente, abriria maiores possibilidades na busca da equidade de gênero.

\section{A Licença-Maternidade: reforço da divisão sexual do trabalho?}

A maternidade talvez seja o principal obstáculo no caminho da emancipação feminina, em virtude da gama de simbologias sociais que traz em si e do forte apelo moral que carrega, sendo, inclusive, assunto delicado dentro do próprio movimento feminista. De maneira geral, o movimento acaba por se dividir entre as mulheres que veem a maternidade como uma das mais fortes ferramentas de submissão feminina pelo patriarcado, quanto pelas que enxergam a singularidade da reprodução pelo corpo feminino como um maior poder. No meio dessas discussões, os extremos acabam por esquecer outro elemento importante para repensar a maternidade e, consequentemente, o peso que ela carrega: o papel da paternidade.

É fato que a dicotomia público/masculino e privado/feminino ainda persiste na nossa sociedade, mesmo com o avanço dos direitos femininos. Essa bipartição, enraizada por milênios de um sistema patriarcal, permanece nas estruturas sociais - embora de maneiras mais sutis -, consolidada por uma cultura que, muitas vezes, impede que homens e mulheres percebam o papel que desempenham na manutenção dessas instituições - mesmo quando conscientes, é difícil que se desembaracem de tais práticas. Assim, "humanidade" passa a ser imperativo masculino, dominante, que define a mulher como o outro, relativa ao homem e não a si mesma (BEAUVOIR, 2016, p. 12)

Assim sendo, a divisão sexual do trabalho, especialmente em relação ao cuidado, escancara o quanto as relações de gênero no Brasil ainda estão permeadas pelo conservadorismo. Pode-se começar a abordar o assunto, propriamente, pelas diversas políticas públicas implementadas de caráter positivo para a maternidade e caráter punitivo para a paternidade, adotando-se, ainda que de maneira irrefletida, uma postura que já rotula o homem como abstendo-se dos cuidados domésticos, inclusive no âmbito paterno. Há dados estatísticos que comprovam esse comportamento masculino, como recente pesquisa 
CONQUISTAS E DESAFIOS DAS POLITICAS PÚBLICAS PARA A MATERNIDADE:

REFLEXÕES SOBRE A LICENÇA PARENTAL COMO INSTRUMENTO DE EQUIDADE DE GÊNERO

do IBGE, que destaca que cerca de 5 milhões de brasileiros não possuem o nome do pai no registro civil. No entanto, no sentido de mudanças estruturais, não teriam o Estado e as políticas públicas um papel fundamental na influência das mudanças de comportamento social?

A implementação de políticas públicas se dá como espaço de disputa no campo democrático, pautada, especialmente, pelas demandas sociais nascidas de políticas de reconhecimento. Ou seja, essas disputas acontecem justamente com o intuito de ressignificar estruturas de poder, já que, como afirma Mouffe (2003, p. 14), não é possível erradicar o poder por si só, visando, assim, a mudanças progressivas nos comportamentos culturais. Dessa forma, ao pensarmos na implementação de políticas sociais que visem à emancipação feminina, compelindo setores da sociedade a reconhecer os direitos das mães, estamos legitimando a luta pela autonomia das mulheres e deslocando o poder patriarcal para um poder de escolhas pessoais das mulheres. Mas isso seria possível sem uma mudança sociocultural sobre como vemos a paternidade?

Ao falarmos em divisão sexual do trabalho, assinalamos não somente as designações profissionais que dicotomizam as mulheres em trabalhos voltados para cuidado e afeto e os homens para funções mais pragmáticas, mas também jornadas triplas de trabalho, em que as mulheres ainda exercem cerca de $73 \%$ de horas a mais que os homens (IBGE, 2018). Não há, portanto, como falar em busca de equidade entre os gêneros sem falarmos do âmbito familiar e das formas de diminuirmos o impacto que o trabalho doméstico e, especialmente, a maternidade têm sobre a dificuldade do alcance da emancipação feminina. Nesse sentido, muitos trabalhadores homens se relacionam com suas paternidades e constroem uma paternagem como forma de repensar a divisão sexual do trabalho a partir da primeira célula social, a família (PINHEIRO, GALIZA, FONTOURA, 2009; MATOS, OLIVEIRA, NATIVIDADE, 2016; MEDRADO, LYRA, OLIVEIRA, AZEVEDO, NANES, FELIPE, 2010). O conceito de paternagem tem sido utilizado para diferenciar, justamente, a simples instituição paternidade de uma paternidade mais participativa. Segundo Abade e Romanelli $(2018$, p. 3), a paternagem é a dedicação "às necessidades físicas e emocionais dos filhos, o que inclui cuidados com alimentação, higiene, saúde, amparo e doação de afeto". Muitos desses estudos apontam que há vontade, por parte de uma parcela dos homens, de assumir os cuidados dos filhos, mas há pouco espaço social para tanto. Ramires (1997, p. 93), ao entrevistar diversos pais, constatou que

\footnotetext{
....as obrigações e responsabilidades fora do lar, na esfera públi$\mathrm{ca}$, portanto, originam nestes homens o sentimento de ter pouco tempo para dedicar aos filhos/às filhas. Originam também, por causa disto, o sentimento de culpa e de dívida para com esses filhos/filhas. Em grande parte, isso se deve à organização social dos papéis do homem e da mulher, e à própria organização do trabalho, que não se baseia na necessidade e no interesse dessa participação
} 
Nota-se, portanto, que a divisão sexual do trabalho prejudica também o exercício da paternagem e lesa tanto a busca pela autonomia das mulheres quanto a própria libertação dos papéis tradicionais de masculinidade dos homens. Nesse sentido, perceber o quanto as políticas sociais implementadas estão permeadas por esses rótulos bipartidos faz-se necessário para repensarmos se, de fato, as políticas públicas para a maternidade têm sido implementadas para diminuir o impacto da desigualdade de gênero ou se, de maneira complexa e sutil, acabam por reforçar o papel da mãe como central na vida dos filhos, esquecendo-se da dualidade da parentalidade.

\section{0 reforço dos estereótipos de gênero e a discussão da Licença Parental}

Percebe-se um paradoxo complexo na sociedade brasileira. Se, por um lado, as mulheres conseguiram, a duras penas e com muita luta, adquirir direitos que tenham a equidade de gênero como meta e, através desses direitos, estejam ganhando maior participação no mercado de trabalho, por outro ainda há um reforço da divisão sexual do trabalho institucionalizada na forma de leis diversas ${ }^{7}$. Aqui nos interessa, em particular, a disparidade da licença-maternidade em comparação com a licença-paternidade. Tal disparidade demonstra, de forma evidente, essa separação de atribuições quanto ao gênero e à necessidade de uma melhor distribuição das tarefas de cuidado, de modo que seja possível promover impactos a longo prazo na estrutura social, já que

...mesmo sendo a relação mãe-filho apenas mais uma relação entre tantas outras, a maternagem e a paternagem estão estruturalmente relacionados a arranjos e formulações ideológicas que acabam justificando a divisão de trabalho por sexos (UNBEHAUM, 1998, p.175).

Isto posto, podemos partir para uma reflexão: de que forma podemos diminuir esse problema? Quais mecanismos usar para mover a sociedade num sentido de transformação sociocultural? As políticas públicas são utilizadas justamente nesse sentido, mas é necessário que se aponte que elas se constituem em um poder paradoxal: ao mesmo tempo que esse poder pode influenciar, também pode ser influenciado através da transformação de demandas em ação coletiva (SCHIMIDT, 2016, p. 47). Portanto, a partir das demandas sociais que vão surgindo, das pressões dos movimentos sociais e, finalmente, da implementação de políticas públicas, é possível criar mecanismos que causem impacto nas estruturas sociais a longo prazo, deslocando esses poderes existentes.

$\mathrm{Na}$ questão da desigualdade entre licença-maternidade e paternidade

7 Segundo Unbehaum (1998, p.176), até pouco tempo o código civil ainda trazia, em seu texto, o estereótipo do homem como "chefe da sociedade conjugal". 
CONQUISTAS E DESAFIOS DAS POLÍTICAS PÚBLICAS PARA A MATERNIDADE:

e diante do fato de a licença-maternidade ser benéfica para mães e bebês e sua garantia tornar-se primordial, é imprescindível que possamos reconhecer o estereótipo que ela reforça na divisão sexual do trabalho. Dessa forma, a alternativa de uma licença parental torna-se muito mais adequada para um caminho não só de emancipação feminina, mas também de uma equidade entre os gêneros. Ademais, a licença parental também se mostra como uma via para a desconstrução de uma masculinidade que se mostra cada vez mais tóxica, não só para a sociedade, mas para os homens em si, já que "a masculinidade é conquistada no final de um combate (contra si próprio) que não raro implica dor física e psíquica" (BADINTER, 1993, p. 70).

Diante desse contexto, portanto, a adoção da licença parental se apresenta como alternativa não apenas para a diminuição da divisão sexual do trabalho, mas também para a desconstrução dessas masculinidades. Isso poderia promover, concomitantemente, uma maior emancipação feminina e a quebra de padrões de gênero relacionados ao cuidado. Ambos os aspectos acabam influenciando os homens de maneira positiva, melhorando a interação familiar e, consequentemente, educando novas gerações para um menor impacto das diferenças entre homens e mulheres.

A licença parental parte do princípio de igualdade de responsabilidade entre pai e mãe, levando em consideração não a tradicional visão biológica dos sexos, que estipula a mãe como a única capacitada para cuidar do filho recém-nascido, mas construindo uma nova perspectiva de contribuição entre os pais, não apenas em relação ao desenvolvimento físico do bebê, mas também psíquico. Além disso, a licença parental poderia ter impacto positivo na economia, já que, com maior incentivo para as mulheres conciliarem mercado de trabalho e maternidade, elas acabam por se tornarem mais produtivas.

Esse foi o pensamento que motivou a implementação da licença parental na Suécia na década de 1970, primeiro país a ter uma política nesse sentido e que nos fornece dados empíricos para a percepção das mudanças que essa política pode causar. As políticas públicas para as mulheres, na Suécia, foram sendo efetuadas como estratégia de superação da quebra da bolsa de 1929, que mergulhou o país em grave crise econômica e social. Essas políticas possibilitaram a inserção das mulheres no mercado de trabalho, contribuindo para o fortalecimento da economia. As mulheres contavam com o amparo de um sistema de ofertas de vagas em creches e, finalmente, com a elaboração de uma licença equitativa entre os pais, a qual, ao longo desses mais de 40 anos, teve um efeito cultural nas relações de gênero na Suécia.

A licença pode ser dividida igualmente entre os pais e aderida de forma alternada, sendo possível usufruí-la de forma integral, com jornada de meio expediente ou de um quarto do tempo. Esse tempo de licença é remunerado para ambos os pais, sendo eles empregados ou não. O que varia no caso dos desempregados é apenas o valor a ser recebido, que corresponde a um teto, enquanto os pais que possuíam emprego antes do nascimento recebem valor 
proporcional aos rendimentos. A licença pode ser solicitada antes do nascimento da criança, já que o afastamento da mãe não é dado necessariamente antes do parto (FARIA, 2000, p. 78).

O que se percebe no modelo sueco é não apenas um amparo total à mãe - que não precisa se dedicar exclusivamente à maternidade durante o período de licença, podendo conciliar uma jornada de trabalho menor com os cuidados com o filho -, mas também um incentivo da paternidade responsável e da diminuição da divisão sexual de tarefas no âmbito doméstico. Depois de quatro décadas de implementação, é possível perceber, concretamente, as consequências dessa política social. Em primeiro lugar, como observa Faria (p.182), a consequência mais direta do sistema de licença parental é como ele influencia no planejamento familiar, fazendo com que os casais planejem não só o primeiro filho - já que quanto mais estabilidade os pais têm em seu emprego, maiores os benefícios, sendo o abono proporcional aos rendimentos e ao tempo de serviço -, como também o intervalo entre os próximos. Além disso, na virada da década de 1980 para a de 1990, os marcadores foram extremamente positivos se comparados ao período anterior: $44 \%$ dos pais usufruíram da licença a partir de 1989, contrastando com apenas $10 \%$ nos primeiros anos da efetivação da lei. Ademais, percebe-se que os pais de crianças pequenas tendem a se envolver de maneira mais dedicada aos cuidados do bebê e também do ambiente doméstico em si.

Notam-se, portanto, inúmeros benefícios trazidos para a sociedade sueca através da execução da licença parental. Nesse ponto, poderíamos defender a adoção do modelo sueco no Brasil, tanto pelas benesses sociais que traz quanto pelas econômicas. No entanto, não poderíamos deixar de destacar que a própria constituição histórico-social do país difere dos países escandinavos, encontrando, portanto, outros percalços em seu caminho.

No contexto latino-americano, a implementação de licenças parentais é recente, sendo que poucos países aderiram essa política. Somente Cuba, Chile e Uruguai possuem, atualmente, uma legislação que permite maior participação dos pais nos cuidados com os filhos, sendo Cuba o país pioneiro, tendo adotado essa política desde 2003 (ANDRADE, 2018, p. 64). No Chile e no Uruguai, as licenças, adotadas respectivamente em 2011 e 2013, ainda nos fornecem poucos dados do impacto social desde sua implementação, mas já esboçam traços interessantes sobre como essas políticas podem influenciar nos comportamentos culturais. É importante assinalar que, em ambos os casos, a licença-paternidade foi instaurada pouco antes da licença parental: no Chile, foi em 1994 e, no Uruguai, em 1990 para funcionários públicos - somente em 2008 ela foi estendida para todo e qualquer trabalhador -; caso distinto do Brasil, onde licença-paternidade vigora desde 1967. Esse dado se torna de extrema relevância, pois influencia diretamente na adesão dos pais ao benefício por questões sociais e culturais.

No Chile, o modelo em vigor possibilita que os pais possam ter de 12 (integral) a 18 (meio período) semanas, a contar, a partir da $7^{\mathrm{a}}$ semana, com 
CONQUISTAS E DESAFIOS DAS POLÍTICAS PÚBLICAS PARA A MATERNIDADE:

REFLEXÕES SOBRE A LICENÇA PARENTAL COMO INSTRUMENTO DE EQUIDADE DE GÊNERO

remuneração total ou parcial por parte do Estado, sendo a mãe quem decide se cede ou não os dias ao pai. No Uruguai, a licença se dá em "meio período restrita a trabalhadores do setor privado, a ser utilizado pelo pai ou mãe, não concomitantemente, após o fim da licença-maternidade, até que o bebê complete 6 meses" (ANDRADE, 2018, p. 102), também sendo o período concedido pela mãe ao pai. Devemos, contudo, frisar que, em ambos os casos, o controle sobre a adesão ou não dos pais se dá por intermédio da mãe, o que acaba por reforçar o monopólio dos cuidados na figura materna.

Em relação aos dados preliminares, percebemos uma repercussão ainda tímida dessas políticas. Andrade (2018) aponta que, desde sua implantação no Chile, até 2014, das 274.264 concessões, apenas 713 mães outorgaram o benefício aos pais (p. 88). No Uruguai, segundo dados do Ministério do Desenvolvimento Social (2017, p. 18), apenas 512 pais usufruíram da licença desde que a lei foi sancionada até o levantamento dos dados, em 2017. No entanto, destaca-se o aumento progressivo dos pedidos, que passaram de 57 no primeiro ano da lei em vigor para 183 no ano da pesquisa. Essa baixa adesão pode ter uma gama de fatores, que vão desde o reconhecimento tardio da licença-paternidade por esses países, passando por desconhecimento da existência do benefício, até fatores intrinsecamente culturais. De fato, o que nos parece é que o reconhecimento do papel do pai nos cuidados da criança e, consequentemente, a diminuição da divisão sexual do trabalho no âmbito doméstico parecem ter forte resistência no contexto latino-americano, o que pode estar vinculado às raízes profundamente cristãs.

Segundo dados do último censo publicado pelo IBGE, de 2010, 86,6\% da população brasileira se declara cristã e, segundo pesquisa realizada pelo Datafolha em 2017, de cada dez brasileiros, três consideram-se evangélicos, o que gira em torno de $29 \%$ da população. Esses dados se revelam importantes para compreendermos algumas características da sociedade brasileira e seu conservadorismo em relação não apenas à discussão de gênero, mas também aos obstáculos que encontramos na produção de mecanismos de mudança em relação à desigualdade entre homens e mulheres, já que ela se sustenta em forte moral cristã. Como afirma Badinter (1985, p. 145), o próprio mito do amor materno provém de duas grandes instituições: Igreja e Estado burguês. Essas instituições, ao imporem comportamentos normatizantes sobre os corpos femininos, garantiam o princípio da autoridade e da hierarquia já na primeira célula social, além de colocarem a criança como foco dos cuidados, tendo em vista não só a herança da propriedade privada - no caso das elites -, como também a manutenção da mão de obra trabalhadora - no caso das classes mais baixas. Isso tudo amparado por uma visão de família sagrada calcada na imagem da Virgem Maria como modelo materno.

Assim, a grande influência da moral burguesa e cristã na sociedade brasileira, bem como a própria constituição histórica do país, construído em bases hierárquicas, patriarcais e escravocratas, contribuem para uma certa aversão 
de setores conservadores da sociedade ao debate sobre relações igualitárias, cujo um dos fatores de justificativa pode ser o debate da licença parental ainda ser incipiente em nosso país.

Ainda que se encontre esses entraves, é necessário que se assinale pequenos movimentos no sentido de tentar trazer o assunto para debate. Em 2008, tivemos a sanção da Lei Empresa Cidadã, que busca, através de incentivos fiscais, estimular que as empresas cadastradas ao programa ampliem a licença-maternidade para 180 dias e concedam aos pais, além dos 5 dias previstos em lei, mais 15 dias de licença paternidade e a participação em cursos de paternidade responsável. Para desfrutar do benefício, o funcionário só precisa entrar com o pedido até dois dias após o nascimento do filho. Com 21.246 empresas adeptas, o programa abarca desde multinacionais até empresas de médio porte. Não foram encontrados, porém, dados específicos sobre número de funcionários que aderiram ao programa.

Na esteira do programa Empresa Cidadã, há também dois projetos que tramitam no Senado Federal. Um deles é a Proposta de Emenda Constitucional 16/2017, assinada por 36 senadores de diversos partidos e espectros políticos diferentes, que prevê a possibilidade de compartilhamento da licença-maternidade entre pai e mãe. A PEC, no entanto, mantém os 120 dias já garantidos como cláusula pétrea na Constituição, o que gera controvérsias já que, no caso de os pais optarem pela divisão da licença, a mãe teria apenas dois meses de afastamento garantido ${ }^{8}$. Já a Proposta de Lei 151/2017, de autoria da Senadora do MDB Rose de Freitas, visa à ampliação dos 120 dias para 180, também contando com a divisão dos dias entre os pais. Prevê, ainda, a ampliação da licença parental para 360 dias caso a criança seja portadora de necessidades especiais, também com a proposta de divisão dos dias concedidos. Ambas as propostas ainda tramitam no Senado sem previsão, até o presente momento, de irem à votação.

É importante também assinalar que, mesmo com duas propostas tramitando atualmente, nenhuma delas menciona cursos de paternidade responsável ou campanhas governamentais que visem a esse fim em suas justificativas ou mesmo no corpo do texto jurídico. Percebe-se que, mesmo com algumas brechas, o assunto não é debatido no âmbito público, com consultas populares ou mesmo com a divulgação de ações que busquem a equidade de gênero nas relações familiares. Apenas implementar uma política pública que vise ao amparo de determinado grupo social não basta. Enquanto mecanismo de mudança socioestrutural, é necessário que se criem estratégias de suporte, como campanhas publicitárias, palestras e a própria difusão dos direitos garantidos desse grupo. Assim, talvez, seja possível amadurecermos o debate acerca da desigualdade de gênero ainda na célula familiar.

8 Em nenhum momento menciona-se flexibilização da jornada, como ocorre na Suécia, o que causa a interpretação que as mães ou teriam abono integral, ou teriam de voltar às suas funções caso optem por ceder parte do período ao pai. 
CONQUISTAS E DESAFIOS DAS POLITICAS PÚBLICAS PARA A MATERNIDADE:

REFLEXÕES SOBRE A LICENÇA PARENTAL COMO INSTRUMENTO DE EQUIDADE DE GÊNERO

\section{Conclusão}

Embora tenhamos adquirido, através de muita luta do movimento feminista e de mulheres, direitos importantes rumo a um caminho de equidade, ainda há muito o que fazer especialmente no debate sobre maternidade, o qual ainda se configura como grande tabu a ser quebrado não apenas na sociedade, mas nos movimentos sociais em si. Falar de maternidade é debatermos não apenas esses laços morais que pesam tanto sobre as mães, como também a responsabilização social não de só um setor em relação aos cuidados com as crianças, mas da sociedade como um todo.

O trabalho afetivo, ainda muito associado restritivamente às mulheres, demanda esforço psicoafetivo e físico que, juntamente com outras exigências sociais, se feito de forma exclusiva, impacta na saúde mental e física de quem o exerce, causando desdobramentos sociais e mantendo a divisão sexual do trabalho, o acesso árduo das mulheres ao mercado de trabalho, as remunerações menores para as mulheres e a perpetuação do papel da mãe como centro da vida dos filhos. Faz-se necessário, portanto, que repensemos as formas como a maternidade vem sendo exercida no nosso contexto social, e isso passa não apenas pela desconstrução do modelo de maternidade, mas também pela construção de uma nova paternidade, mais participativa, com mais afeto e cuidados, além da adoção, por parte do Estado, de políticas que beneficiem essa mudança comportamental, acompanhando as novas demandas que se apresentam.

Nesse sentido, a licença parental se mostra como ferramenta de possíveis transformações, o que se pode inferir a partir da análise feita dos modelos vigentes, seja o sueco, que possui maior tradição e gama de dados, sejam os recentes modelos latino- americanos, que, possivelmente, nos darão elementos mais concretos nos próximos anos. É interessante que possamos pensar em formas de estender esse debate à sociedade brasileira, adaptando as políticas já existentes para o contexto local, especialmente em um momento de intensas transformações político-sociais. Essas mudanças, que caminham para um espectro de conservadorismo autoritário, reforçam muitos dos preconceitos que se referem à quebra de estereótipos de gênero, especialmente quando se trata de remodelar os papéis parentais.

Dentre os motivos de resistência, podemos citar uma forte influência da moral cristã, especialmente em um país onde as igrejas pentecostais crescem de forma acelerada, muitas se utilizando-se justamente dessa visão tradicional de família para ancorar seus dogmas conservadores. Isso se reflete, especialmente, na composição do congresso nas duas últimas eleições, em que a bancada evangélica aumentou consideravelmente e acabou por se tornar oposição a diversos textos que entraram em votação voltados à promoção da igualdade de gênero e à emancipação feminina. Além disso, mesmo setores progressistas como algumas esferas do movimento feminista se mostram hesitantes quanto à licença parental por não crerem que os homens a utilizarão 
de forma a voltarem-se, de fato, para a divisão de cuidados aos filhos com suas companheiras. Mas, por acaso, não seria possível criar uma prática que vise às mudanças comportamentais através do Estado, com a imposição de um teto de dias a ser usufruído pelo pai, juntamente com campanhas intensas de conscientização rumo a uma paternidade participativa?

O que percebemos é um profundo arraigamento dos estereótipos de gênero e da construção social que fizemos (e fazemos) em torno da masculinidade. Se, por um lado, temos homens que lutam pela manutenção de seu privilégio dentro de uma sociedade estratificada por um modelo patriarcal, por outro, assumimos que todos eles tendem a não abrir mão dessa figura construída do pai ausente. Eis aí que encontramos a falha em generalizarmos os grupos sociais, dando pouca margem ao papel de agente que os indivíduos podem ter mesmo inseridos na estrutura. A própria necessidade de políticas que contemplem a paternidade participativa é demanda de grupos de homens que lutam pelo reconhecimento da paternagem, tal como o instituto Papai, localizado em Recife. O aumento do número de pais com guarda compartilhada cresceu de 7,5\% para 12,9\% em 2015, de acordo com dados do Conselho Nacional de Justiça, o que demonstra maior predisposição dos pais em estarem presentes nos cuidados dos filhos.

Dessa forma, a licença parental traz possíveis benefícios que impactam nas esferas familiar, social e até mesmo econômica. No âmbito familiar, ela diminui o impacto da divisão sexual do trabalho, reconhece a paternidade como fundamental na constituição da psique da criança, promove uma divisão das responsabilidades que beneficia pai e mãe. Na esfera social institui a equidade de gênero nos cuidados dos filhos, promovendo, a longo prazo, nas gerações futuras, novas formas de ver o que é ser homem e o que é ser mulher, desconstrói uma masculinidade criada em torno de agressividade e do distanciamento e promove um caminho para a emancipação das mulheres. Por fim, no âmbito econômico, proporciona funcionários mais produtivos, especialmente as muIheres, já que retira a sobrecarga da maternidade, se pensada da forma como ocorre na Suécia, com abono proporcional aos ganhos, viabilizando melhor planejamento família, com vistas a uma maior estabilidade e alavancando o número de mulheres no mercado de trabalho.

Assim, olharmos com cuidado para a paternidade como peça fundamental do caminho de equidade de gênero proporciona inúmeros benefícios tanto para mulheres quanto para homens. Não podemos mais negar que, somente com o empoderamento feminino e com políticas públicas voltadas à promoção da liberdade feminina, conseguiremos, de fato, a equidade de gênero. Isso porque, na teia social em que nos encontramos, também precisamos pensar no "outro lado" para diminuir a dominação masculina, fomentar uma masculinidade mais saudável e fazer com que os próprios homens vejam a necessidade de uma sociedade mais igualitária. 
CONQUISTAS E DESAFIOS DAS POLITICAS PÚBLICAS PARA A MATERNIDADE:

REFLEXÕES SOBRE A LICENÇA PARENTAL COMO INSTRUMENTO DE EQUIDADE DE GÊNERO

\section{Referências bibliográficas}

ANDRADE, Luiza Lobato. Gênero, trabalho e bem-estar social na América Latina: um estudo das políticas de licenças maternidade, paternidade e parentais no Brasil, Chile e Uruguai. 2018. p. 127. Dissertação (Mestrado em Ciências Sociais) - Departamento de Estudos Latino-Americanos, Universidade de Brasília, Brasília,

BADINTER, Elisabeth. XY: Sobre a identidade masculina. 1. ed. Rio de Janeiro: Nova Fronteira, 1993.

BADINTER, Elisabeth. Um amor conquistado: o mito do amor materno. 1. ed. Rio de Janeiro: Nova Fronteira, 1985.

BEAUVOIR, Simone. O segundo sexo. 2. ed. Nova Fronteira, 2014.

BESSE, Susan Kent. Modernizando a desigualdade: reestruturação da ideologia de gênero no Brasil, 19141940. 1. ed. São Paulo: Edusp, 1999.

BRASIL, Lei de Diretrizes e Bases. Lei no 9.394/96, de 20 de dezembro de 1996. Disponível em: http://portal.mec. gov.br/seesp/arquivos/pdf/lei9394_Idbn1.pdf Acesso em: 29 de abr. 2018

BRASIL. Consolidação das Leis do Trabalho. Decreto-Lei n 5.442, de 01.mai.1943. Disponível em: http://www. planalto.gov.br/ccivil_03/Decreto-Lei/Del5452compilado.htm. Acesso em: 29.Abril.2018

BRASIL. Constituição (1988). Constituição da República Federativa do Brasil. Brasília, DF: Senado Federal: Centro Gráfico, 1988

FARIA, Carlos Aurelio Pimienta de. Entre marido e mulher, o estado mete a colher: reconfigurando a divisão do trabalho doméstico na Suécia. Red Revista Brasileira de Ciências Sociais, 2000.

KERGOAT, Daniele. Divisão sexual do trabalho e relações sociais de sexo. In: TEIXEIRA, Marilane; EMÍLIO, Marli; NOBRE, Miriam; GODINHO, Tatau (org). Trabalho e cidadania ativa para as mulheres: desafios para as Políticas Públicas. São Paulo: Coordenadoria Especial da Mulher, p. 55-63, 2003

LAQUEUR, Thomas. Inventando o sexo. 1. ed. Rio de Janeiro: Relume Dumará, 2001.

MARSHALL, Thomas Humphrey. Cidadania e classe social. 1. ed. Rio de Janeiro: Zahar Editora, 1967.

MARTINS, Ana Paula Vosne. Políticas públicas para a maternidade e a infância no Brasil na primeira metade do século XX. In: MONTEIRO, Yara Nogueira (org.) História da saúde: olhares e veredas. 2010. p. 99-121

MATOS, Ana Carla Harmatiuk; DE OLIVEIRA, Ligia Ziggiotti; DE NATIVIDADE, João Pedro Kostin Felipe. Licença parental como agenda para a igualdade de gênero: Diálogos entre os modelos sueco e brasileiro. Revista da Faculdade de Direito UFPR, v. 61, n. 3, p. 345-363, 2016.

MEAD, Margareth. Sexo e Temperamento. 5. ed. Rio de Janeiro, Perspectiva: 2009

MOUFFE, Chantal. Democracia, cidadania e a questão do pluralismo. Política \& Sociedade, v. 2, n. 3, p. 11-26, 2003.

PINHEIRO, Luana; GALIZA, Marcelo; FONTOURA, Natália. Novos arranjos familiares, velhas convenções sociais de gênero: a licença-parental como política pública para lidar com essas tensões. Revista estudos feministas, v. 17, n. 3, p. 851-859, 2009.

PINTO, Céli Regina J. Uma história do feminismo no Brasil. 1. ed. São Paulo: Editora Perseu Abramo, 2003.

RAMIRES, Vera Regina. O exercício da paternidade hoje. 1. ed. Editora Record, 1997.

REA, Marina. Benefícios à mãe trabalhadora: conquistas e recuos nas políticas públicas. In: BRUSCHINI, Cristina; UNBEHAUM, Sandra G. (Org.). Gênero, democracia e sociedade brasileira. São Paulo: Ed. 34, 2002.

SCHMIDT, João Pedro. Condicionantes e diretrizes de políticas públicas: um enfoque comunitarista da transformação social. Revista Brasileira de Políticas Públicas, v. 6, n. 3, 2017.

SCOTT, Joan. Gênero: uma categoria útil de análise histórica. Educação \& Realidade. Porto Alegre, vol. 20, n², pp. 71-99, 1995

SILVEIRA, Maria Lucia (Org.). Políticas públicas e igualdade de gênero. São Paulo: Coordenadoria Especial da Mulher, 2004. p. 169-182.ABADE, Flávia; ROMANELLI, Geraldo. Paternidade e paternagem em 
maternidade e paternagem em famílias patrifocais. Revista Estudos Feministas, v. 26, n. 2, 2018.

UNBEHAUM, Sandra. A desigualdade de gênero nas relações parentais: o exemplo da custódia dos filhos. In ARILHA, Margareth; UNBEHAUM, Sandra; MEDRADO, Bendito. Homens e Masculinidades: Outras Palavras. São Paulo: Editora 34. 1998. p. 163-184WALBY, Sylvia. Cidadania e transformações de gênero. In: TATAU, Godinho;

URUGUAY. Informe de investigación: Sensibilización para el uso del subsidio de medio horario por parte de los varones padres. Montevidéo: Grupo Pértiga, 2017. Disponível em: http://www. sistemadecuidados.gub.uy/innovaportal/file/93257/1/sensibilizacion-para-el-uso-del-subsidio-de-mediohorario-por-parte.pdf Acesso em: 30 de dezembro de 2018

WITTER, Nikelen Acosta. Dizem que foi feitiço: as práticas da cura no sul do Brasil (1845 a 1880). 1. ed. Edipucrs, 2001. 